\title{
Clinico-demographic Characteristics of Coronary Artery Bypass Surgery Patients: Experience of 60 Cases at Referral Cardiac Surgery Hospital in Bangladesh
}

\author{
Asraful Hoque ${ }^{1}$, Farooque Ahmed ${ }^{2}$, KAM Mahbub Hasan ${ }^{3}$, Romena Rahman ${ }^{4}$
}

\begin{abstract}
Background: Coronary artery bypass surgery is needed in different group of patients.Objective: This study was undertaken to see the different socio-demographic characteristics of patients undergone coronary artery bypass surgery. Methodology: This cross-sectional study was conducted in the Department of Cardiac Surgery at National Institute of Cardiovascular Diseases (NICVD), Dhaka, Bangladesh during January 2014 to December 2015 for a period of two (2) years. Patients' undergone CABG after fulfilling the inclusion and exclusion criteria was recruited for this study. The details sociodemographic characteristics of the study population were recorded. Result: A total number of 60 patients were recruited for this study after fulfilling the inclusion and exclusion criteria. The age of the patients undergoing $\mathrm{OPCAB}$ surgery ranges from 37 years to 70 years. But most of the patients were in the range of 41 to 60 years which was 50(83.3\%). There was an overall male dominance among the patients which was $91.67 \%$. the ratio of male and female was 11.0:1. NYHA class I was in 32(53.3\%) cases and class II was $28(46.47 \%$ ) cases. Hypertension was present in $37(63.3 \%)$ cases. Diabetes mellitus and dyslipidemia were present in 50(83.3\%) cases and $37(61.7 \%$ ) cases respectively. Obesity was present in $40(66.7 \%)$ cases. Smoking habit was present in 34(56.7\%) cases. Conclusion: In conclusion the efficacy of topical tranexamic acid is helpful for reducing postoperative bleeding after OPCAB surgery. [Journal of Science Foundation, 2016;14(2):62-65]
\end{abstract}

Keywords: Coronary artery bypass surgery; demographic characteristics; cardiac surgery

[Received: 2 January 2016; Revised: 29 March 2016; Accepted: 12 May 2016; Published: 1 July 2016]

\section{Introduction}

Incidence of ischemic heart disease is increasing in developing countries including Bangladesh. In 1975, the incidence of IHD in Bangladesh was reported to be 3.3 per thousand (Christensen et al., 2009) and that in 1985 was 14 per thousand (Brown et al., 2007). According to the latest WHO data published in April 2011 Coronary Heart Disease Deaths in Bangladesh reached 163,769 or 17.11\% of total deaths and Bangladesh ranks $25^{\text {th }}$ position in the world in respect to cause of death due to coronary artery disease (Hartmann et al., 2006).

Bleeding is a common complication after CABG (Abrishami et al., 2009). Excessive bleeding and blood transfusion play an important role in post-CABG mortality and morbidity. Patients undergoing cardiac surgery still receive more blood transfusions than in other surgical procedures, consuming $20 \%$ of blood bank reserves. Reopening sternotomy to control bleeding has been reported in 2 to $7 \%$ of cases. Blood transfusion can cause infection and immunological reactions and increase hospital length stay and cost,

\footnotetext{
${ }^{1}$ Resident Surgeon, Department of Cardiac Surgery, National Institute of Cardiovascular Diseases, Dhaka, Bangladesh

${ }^{2}$ Professor \& Chief Cardiac Surgeon, Department of Cardiac Surgery, National Heart Foundation Hospital \& Research Institute, Dhaka, Bangladesh

${ }^{3}$ Medical Officer, Department of Cardiology, National Institute of Cardiovascular Diseases, Dhaka, Bangladesh

${ }^{4}$ Medical Office, Cardiac Surgery Outpatients Department, National Institute of Cardiovascular Diseases, Dhaka, Bangladesh
}

Correspondence: Dr. Asraful Hoque, Resident Surgeon, Department of Cardiac Surgery, National Institute of Cardiovascular Diseases, Sher-e-Bangla Nagar, Dhaka-1207, Bangladesh; Email: dr_asraf_sium@yahoo.com; Cell No.: +8801720834878 
which justifies all efforts to reduce bleeding after CABG (Nourei et al., 2013). The present study was undertaken to see the different socio-demographic characteristics of patients undergone coronary artery bypass surgery.

\section{Methodology}

This study was designed as cross-sectional study. This study was conducted in the department of cardiac surgery at National Institute of Cardiovascular Diseases, Dhaka, Bangladesh from January 2014 to December 2015 for a period of two (2) years. The study was carried out among the patients admitted in NICVD for OPCAB surgery. Approval for this study protocol was taken from the institutional ethical review committee. The purpose of the study was explained to the potential participants. Interests of the study were given the highest priority and confidentiality was maintained with safeguard of the right and health of the participants. Patients with ischemic heart disease admitted in NICVD with a plan for OPCAB Surgery with the age of the patients were within 18 to 60 years in both male and female were include for this study. Data were collected in a case record form (CRF) from history, physical examination, investigation reports. The numerical data obtained from the study were analyzed and significance of difference was estimated by using the statistical methods. Qualitative data are expressed in frequency with corresponding percentage and quantitative data are expressed in mean with standard deviation. All data were analyzed by SPSS 20.0 for Windows ${ }^{\circledR}$.

\section{Result}

A total number of 60 patients were recruited for this study after fulfilling the inclusion and exclusion criteria. The age of the patients undergoing OPCAB surgery ranges from 37 years to 70 years. But most of the patients were in the range of 41 to 60 years which was 50(83.3\%) (Table 1).

Table 1: Distribution of the Patients According To Age

\begin{tabular}{|l|c|c|}
\hline Age Group & Frequency & Percentage \\
\hline 37 to 40 Years & 2 & 3.33 \\
\hline 41 to 50 Years & 26 & 43.33 \\
\hline 51 to 60 Years & 24 & 40.00 \\
\hline 61 to 70 Years & 8 & 13.33 \\
\hline Total & 60 & 100.0 \\
\hline Mean \pm SD & \multicolumn{2}{|c|}{$52.0 \pm 7.0$} \\
\hline
\end{tabular}

Figures in the parenthesis denote corresponding \%; Data were analyzed using chi-square Test

There was an overall male dominance among the patients which was $91.67 \%$. the ratio of male and female was 11.0:1 (Table 2).

Table 2: Distribution of the Patients According To Sex

\begin{tabular}{|l|c|c|}
\hline Gender & Frequency & Percentage \\
\hline Male & 55 & 91.67 \\
\hline Female & 5 & 8.33 \\
\hline Total & $\mathbf{6 0}$ & $\mathbf{1 0 0 . 0}$ \\
\hline
\end{tabular}

Figures in the parenthesis denote corresponding \%; Data were analyzed using $\chi^{2}$ Test

NYHA class I was in 32(53.3\%) cases and class II was 28(46.47\%) cases. Hypertension was present in $37(63.3 \%)$ cases. Diabetes mellitus and dyslipidemia were present in 50(83.3\%) cases and 37(61.7\%) cases respectively. Obesity was present in $40(66.7 \%$ ) cases. Smoking habit was present in 34(56.7\%) cases (Table $3)$. 
Table 3: Distribution of the Patients According to Base Line Clinical Characteristics

\begin{tabular}{|c|c|c|c|c|}
\hline \multicolumn{3}{|c|}{ Base Line Characteristics } & Frequency & Percentage \\
\hline \multirow[t]{4}{*}{ NYHA class } & \multicolumn{2}{|c|}{ Class I } & 32 & 53.33 \\
\hline & \multicolumn{2}{|c|}{ Class II } & 28 & 46.47 \\
\hline & \multicolumn{2}{|c|}{ Class III } & 0 & 0.0 \\
\hline & \multicolumn{2}{|c|}{ Class IV } & 0 & 0.0 \\
\hline \multirow[t]{8}{*}{ Comorbidities } & \multirow[t]{2}{*}{ Hypertension } & Present & 38 & 63.33 \\
\hline & & Absent & 22 & 36.67 \\
\hline & \multirow{2}{*}{$\begin{array}{l}\text { Diabetes } \\
\text { mellitus }\end{array}$} & Present & 50 & 83.33 \\
\hline & & Absent & 10 & 16.67 \\
\hline & \multirow[t]{2}{*}{ Dyslipidemia } & Present & 37 & 61.67 \\
\hline & & Absent & 23 & 8.33 \\
\hline & \multirow[t]{2}{*}{ Obesity } & Present & 40 & 66.67 \\
\hline & & Absent & 20 & 33.33 \\
\hline \multirow[t]{2}{*}{ Smoking habit } & \multicolumn{2}{|c|}{ Present } & 34 & 56.67 \\
\hline & \multicolumn{2}{|c|}{ Absent } & 26 & 43.33 \\
\hline \multirow{2}{*}{$\begin{array}{l}\text { Preoperative } \\
\text { Anti-platelet }\end{array}$} & \multicolumn{2}{|c|}{ Present } & 20 & 33.33 \\
\hline & \multicolumn{2}{|c|}{ Absent } & 40 & 66.67 \\
\hline
\end{tabular}

Figures in the parenthesis denote corresponding $\% ; \chi^{2}$ Test were used to analyze datal

The mean with SD haematocrit, platelet count, INR, bleeding time and clotting time were $41.53 \pm 2.38$, $245.75 \pm 37.11,1.05 \pm 0.09,4.24 \pm 0.49$ and $5.89 \pm 0.41$ (Table 4).

Table 4: Distribution of the patients according to preoperative investigation profile

\begin{tabular}{|l|c|}
\hline Investigation Profiles & Mean \pm SD \\
\hline Haematocrit $(\%)$ & $41.53 \pm 2.38$ \\
\hline Platelet count $\left(\times 10^{9} / \mathrm{cmm}\right)$ & $245.75 \pm 37.11$ \\
\hline INR & $1.05 \pm 0.09$ \\
\hline Bleeding time (min) & $4.24 \pm 0.49$ \\
\hline Clotting time (min) & $5.89 \pm 0.41$ \\
\hline
\end{tabular}

Data were analyzed using Student's t-Test and presented as mean \pm SD

\section{Discussion}

National Institute of Cardiovascular Diseases, Dhaka, Bangladesh plays a pivotal role in the field of cardiac surgery in the country. Yearly about one thousand heart surgeries are performed here. Number of OPCAB surgeries is nearly $20 \%$ of the total procedures performed. Mean $( \pm \mathrm{SD})$ age of the study subjects was $52.97( \pm 7.44)$ years. Age of the most of the patients was between 41 to 60 years. Jares et al (2007) reported the mean age of patients undergoing OPCAB surgery to be $53.80 \pm 8.57$ years which are similar to this study.

Male sex was more common than female among the study subjects. There was an overall male predominance among the patients which was $91.67 \%$. The ratio of male and female was 11.0:1. Khalil et al (2004) also reported a male preponderance in patients undergoing OPCAB surgery.

Baseline clinical characteristics in the study subjects are recorded. Patients were in NYHA class I and class II and no patients were in NYHA III or IV. Most of the patients were hypertensive, diabetic, obese, dyslipidemic. NYHA class I was in 32(53.3\%) cases and class II was 28(46.47\%) cases. Hypertension was present in 37(63.3\%) cases. Diabetes mellitus and dyslipidemia were present in 50(83.3\%) cases and 
$37(61.7 \%)$ cases respectively. Obesity was present in 40(66.7\%) cases. Smoking habit was present in $34(56.7 \%)$ cases. Fergusson et al (2008) reported $48.3 \%$ prevalence of DM respectively. Prevalence of preoperative hypertension was $65.5 \%$. The study subjects were comparable in terms of preoperative patient characteristics and cardiopulmonary functional status.

Preoperative coagulation profiles of were recorded. The haematocrit, platelet count, INR, bleeding time and clotting time were measured. The mean with SD haematocrit, platelet count, INR, bleeding time and clotting time were $41.53 \pm 2.38,245.75 \pm 37.11,1.05 \pm 0.09,4.24 \pm 0.49$ and $5.89 \pm 0.41$. Christensen et al (2009) reported in a study of OPCAB surgery with haematocrit $41.86 \pm 8.35 \%$, platelet count $206852 \pm 76272 / \mathrm{cu} \mathrm{mm}$. These findings were nearly similar to our study.

\section{Conclusion}

In conclusion coronary artery bypass surgery is more commonly performed among male middle age person. Furthermore majority are the history of diabetes mellitus and hypertension. Further lasrge scale study can be performed to get the scenario of Bangladeshi people.

\section{References}

Abrishami A, Chung F, Wong J. Topical application of antifibrinolytic drugs for on-pump cardiac surgery: a systematic review and meta-analysis. Canadian Journal of Anesthesia 2009;56(3):202-12

Baric D, Biocina B, Unic D, Sutlic Z, Rudez I, Vrca VB, Brkic K, Ivkovic M. Topical use of antifibrinolytic agents reduces postoperative bleeding: a double-blind, prospective, randomized study. European Journal of Cardio-thoracic Surgery 2007;31(3):366-71

Brown JR, Birkmeyer NJ, O'Connor GT. Meta-analysis comparing the effectiveness and adverse outcomes of antifibrinolytic agents in cardiac surgery. Circulation 2007;115(22):2801-13

Christensen MC, Krapf S, Kempel A, von Heymann C. Costs of excessive postoperative hemorrhage in cardiac surgery. Journal of Thoracic and Cardiovascular Surgery 2009;138(3):687-93

Fergusson DA, Hébert PC, Mazer CD, Fremes S, MacAdams C, Murkin JM, et al. A comparison of aprotinin and lysine analogues in high-risk cardiac surgery. New England Journal of Medicine 2008;358(22):2319-31

Hartmann M, Sucker C, Boehm O, Koch A, Loer S, Zacharowski K. Effects of cardiac surgery on hemostasis. Transfusion Medicine Reviews 2006;20(3):230-41

Jares M, Vanek T, Bednar F, Maly M, Snircova J, Straka Z. Off-pump versus on-pump coronary artery surgery. International Heart Journal 2007;48(1):57-67

Khalil PN, Ismail M, Kalmar P, von Knobelsdorff G, Marx G. Activation of fibrinolysis in the pericardial cavity after cardiopulmonary bypass. Thrombosis and haemostasis 2004;92(3):568-74.

Masakazu A, et al. Local administration of tranexamic acid in off-pump coronary artery bypass, Asian Cardiovascular and Thoracic Annals 2012;20(6):658-662 